\title{
Association between maternal depressive symptoms with child malnutrition or child excess weight
}

Thais Feres Moreira Lima 1

Warles Melo Maciel 2

Monyk Neves de Alencar 3

Joana Athayde da Silva Cruz 4

Carolina Abreu de Carvalho 5

Antônio Augusto Moura da Silva 6

1-6 Departamento de Saúde Pública. Universidade Federal do Maranhão. Rua Barão de Itapary, 155. Centro. São Luís, MA, Brasil. CEP: $65.020-070$.

E-mail: warles_melo@hotmail.com

\begin{abstract}
Objectives: to verify associations between maternal depressive symptoms with child malnutrition or child excess weight.

Methods: prospective study with data from the BRISA prenatal cohort in São Luis, Brazil, obtained from the 22nd to the 25th week of gestation (in 2009 and 2010) and, later, when children were aged 12 to 32 months (in 2010 and 2012). Maternal depressive symptoms were identified using the Center for Epidemiologic Studies Depression Scale (CES-D) and the Edinburgh Postnatal Depression Scale (EPDS). For the excess weight evaluation, BMI zscore for age $>+2$ was used. For measuring child malnutrition, height $z$-score for age $<-2$ was used. The confounding factors were identified using a directed acyclic graph in DAGitty software.

Results: we did not find associations between maternal depressive symptoms with child malnutrition or child excess weight. The prevalence of maternal depressive symptoms was $27.6 \%$ during gestation and $19.8 \%$ in the second or third year of the child's life. The malnutrition rate was $6 \%$ and the excess weight rate was $10.9 \%$.

Conclusions: no associations between maternal depressive symptoms in prenatal or in the second or third year of the child's life and child malnutrition or excess weight were detected.

Key words Depression, Malnutrition, Overweight, Child, Pregnant women
\end{abstract}




\section{Introduction}

Low weight or excessive weight gain are related to various health problems in childhood, as observed in the United States in children aged between 3 and 6 years. 1,2 The prevalence of overweight and obesity has increased worldwide. ${ }^{3}$ This trend is also being observed among children. ${ }^{4}$ In Brazil, in a cohort conducted in Pelotas - RS, with children up to 48 months, a prevalence of $12.2 \%$ of excess weight in children was found. In the same study, a prevalence of $1.7 \%$ for undernourished and $3.6 \%$ for malnutrition was estimated. While excess weight in infancy is becoming more frequent, malnutrition and low weight are declining. ${ }^{5}$

The role of maternal depression in the development of the child has been questioned in the literature.2,6,7 It is known that gestation and the puerperium are periods of a woman's life involving innumerable physical, hormonal and psychic changes, which may impact directly in her mental health. Studies show that about one-fifth of women has depressive symptoms in the gestational period and that undiagnosed and untreated psychiatric disorders in pregnant women can lead to serious maternal-fetal consequences. 8,9 Mothers with depressive symptoms tend to have difficulty in establishing a bond with their children and are thus more prone to early interruption of exclusive breastfeeding and early introduction of complementary feeding. ${ }^{5}$ Ertel et al.,1 found that children of mothers with symptoms of postpartum depression presented a higher degree of excess weight than children of mothers without depressive symptoms. Surkan et al.,10 found an association between prenatal depressive symptoms and the development of overweight in children aged between 6 to 24 months

In developing countries children of postpartum depressive mothers have a higher risk of being malnourished. ${ }^{11}$ Rahman et al., 12 reiterate that the reduction in prevalence of prenatal and postpartum depression could lead to a reduction in cases of child malnutrition of up to $30 \%$. They also verified that children of mothers with depressive symptoms had a higher risk of growth deficit and of contracting gastrointestinal infections, such as diarrhea. 12 Harpham et al., 11 detected a 1.4-fold higher risk of malnutrition among children of depressive mothers in India and Peru. However, this association was not corroborated by several other studies. 13,14

Studies on the association between maternal depression and child nutrition present controversial results. There are few studies evaluating these associations between maternal depressive symptoms in prenatal or in the first years of child's life and child excess weight or malnutrition. Thus, this study aims to examine whether there are associations between maternal depressive symptoms with the development of child excess weight or malnutrition.

\section{Methods}

This prospective cohort study was performed using data from the BRISA project (Brazilian Ribeirão Preto and São Luís Birth Cohorts), which was performed from January 2009 to March 2012. The studied cities were São Luís - MA and Ribeirão Preto - SP, but only data from São Luís prenatal birth cohort were used in this study.

The sample was obtained by convenience, due to the difficulty of obtaining a random sample, since there are no lists of pregnant women doing prenatal care available. Women were recruited in four prenatal and ultrasonography services in São Luís MA. We interviewed 1,440 women with singleton pregnancies and gestational age from 22 to 25 weeks, confirmed by obstetric ultrasonography performed before the 20th week of gestational age. At birth, 1,381 women attended a new interview and 1,377 were evaluated again in the second or third year of child's life.

In the prenatal period, a standardized questionnaire and the Center for Epidemiologic Studies Depression Scale (CES-D) 15 were applied at the time of the interview. Identification data, as well as socioeconomic, demographic, sexual and reproductive health ones were collected.

The variables collected at the prenatal interview were maternal age $(<20,20$ to 34 or $\geq 35$ years $)$, marital status (single, married or consensual union), maternal schooling ( 1 to 4,5 to 8,9 to 11 or $\geq 12$ years of study), self-reported skin color (white, black or brown), number of children ( 1 or $\geq 2$ ), planned pregnancy (yes or no) and monthly family income in minimum wages (MW, equivalent to $\mathrm{R} \$ 788$ reais in 2015 , and classified into $\mathrm{MW} \leq 1,1<\mathrm{MW}<2,2 \leq$ $\mathrm{MW}<3,3 \leq \mathrm{MW}<5, \mathrm{MW} \geq 5$ ).

At birth, two questionnaires were used, the first one on maternal characteristics and maternal morbidity, and characteristics of childbirth. The second one was about characteristics of the newborn, including anthropometric data. The gender (male or female) and birth weight of the child in grams $(<$ 1500,1500 to 2499,2500 to 3999 or $\geq 4000$ ) variables were used in this study.

In the second or third year of the child's life, a standardized questionnaire was used to collect sociodemographic data and anthropometric charac- 
teristics (weight and length/height). The studied variables were age of the child in months at the time of interview (12 to 23 or 24 to 32 months), weight and length/height. In this interview, the Edinburgh Postpartum Depression Scale (EPDS) was applied. ${ }^{16-18}$

The weight of children was measured using Filizola ${ }^{\circledR}$ electronic scales, by direct measurement with minimum clothes for children $\geq 2$ years. The length was measured by Alturexata ${ }^{\circledR}$ wood anthropometer. The WHO measurement technique was used. ${ }^{19}$ Children under 2 years of age had their length measured immediately after their weight had been measured, keeping them naked with their backs to the surface of the anthropometer, feet flat on the stirrup, legs in extension, spinal alignment and central look. Children aged two years and over had their height measured without the use of shoes, socks or other accessories.

The excess weight was evaluated by the $z$-score of the body mass index for age (BAZ). BAZ $2 \mathrm{z}-$ scores above the mean for each age and sex were considered as excess weight. 20 Malnutrition was evaluated by the z-score of height for age (HAZ) as proposed by Onis et al..21 HAZ 2 z-scores below the mean for each age and sex was used as the cutoff point to detect malnutrition. Z-scores were calculated in the WHO AntroPlus ${ }^{\circledR}$ software version 1.0.4.22

Prenatal maternal depressive symptoms were identified by the Center for Epidemiologic Studies Depression Scale (CES-D), elaborated by the National Institute of Mental Health. The CES-D scale is based on a planned inventory designed for populations with non-clinical diagnoses that aims to identify depressive mood symptoms in the last week before the interview. It is intended for application in population studies. The scale includes 20 items scored from 0 to 3 points with a maximum score of 60 points. The answers are ordered from never, seldom, most often or always; items 4, 8, 12 and 16 are inverted, as they evaluate positive aspects. 15

There are studies on the CED-D scale that indicate a sensitivity of 0.95 and specificity of 0.70 for clinical depression compared to the Diagnostic Interview Schedule for the Diagnostic and Statistical Manual of Mental Disorders (DSM-IV). The cut-off point used was based on studies by Li, Liu \& Odouli, who proposed a cut-off of 22 points or more for detection of severe depressive symptoms. ${ }^{23}$

In the evaluation of symptoms of maternal depression in the second or third year of child's life, the Edinburgh Postnatal Depression Scale (EPDS) was used. It evaluates the presence and intensity of depressive symptoms in the last seven days. The scale contains 10 items scored from 0 to 3 points, added to a maximum score of 30 points. Items 3,5 , $6,7,8,9,10$ are reversely scored, since they evaluate negative aspects about the women's depressive state. There are studies that report sensitivity of 0.68 and specificity of 0.97 , with positive predictive values and negative predictive values of 0.91 and 0.89 for the 12-point cut-off. This study considered the cut-off point $\geq 12$ to indicate maternal depressive symptoms. $16-18$

The data were analyzed by the Stata ${ }^{\circledR}$ software version 12.0 (Stata Corp., College Station, USA). Descriptive and analytical analysis were used for sociodemographic variables, nutritional status of the child and maternal depressive symptoms evaluated by the CES-D and EPDS scales, describing mean, standard deviation and frequency distribution. A $95 \%$ confidence interval was also calculated.

The chi-square test was used to investigate the unadjusted associations between maternal depressive symptoms and infant nutrition. Logistic regression was used to estimate odds ratios (OR) adjusted for the confounding factors: maternal age and the number of children for the outcome child malnutrition. The models were adjusted for maternal schooling, number of children and family income for the outcome child excess weight. The level of significance was set at 0.05 .

The variables suggested to be included in the minimum set of adjustment for confounding were identified by means of a directed acyclic graph (DAG) in the DAGitty ${ }^{\circledR}$ version 2.3 program (Figure $1 \mathrm{~A}$ and $1 \mathrm{~B})$. DAG is a graphical tool that assists in choosing variables to be included in the adjustment following the back door criterion that minimizes problems of bidirectional covariance. ${ }^{24}$

In compliance with Resolution 196/96 of the National Health Council for the regulation of research with human beings, in the present study, the interviewees were invited to participate in the research by agreeing and signing the Term of Free and Informed Consent, being allowed to withdraw without harm for them or for others. The research was approved in the Research Ethics Committee of the University Hospital Presidente Dutra under opinion number 4771/2008 - 30 .

\section{Results}

In the sample of 1381 women, $81.3 \%$ were aged from 20 to 34 years with mean age of 26.1 years (SD $\pm 5.6)$. There was a predominance of self-reported brown skin color, with $68.4 \%$. 
Theoretical model for investigating the association between maternal depressive symptoms with child malnutrition or excess weight.

A - Maternal depressive symptoms and child malnutrition

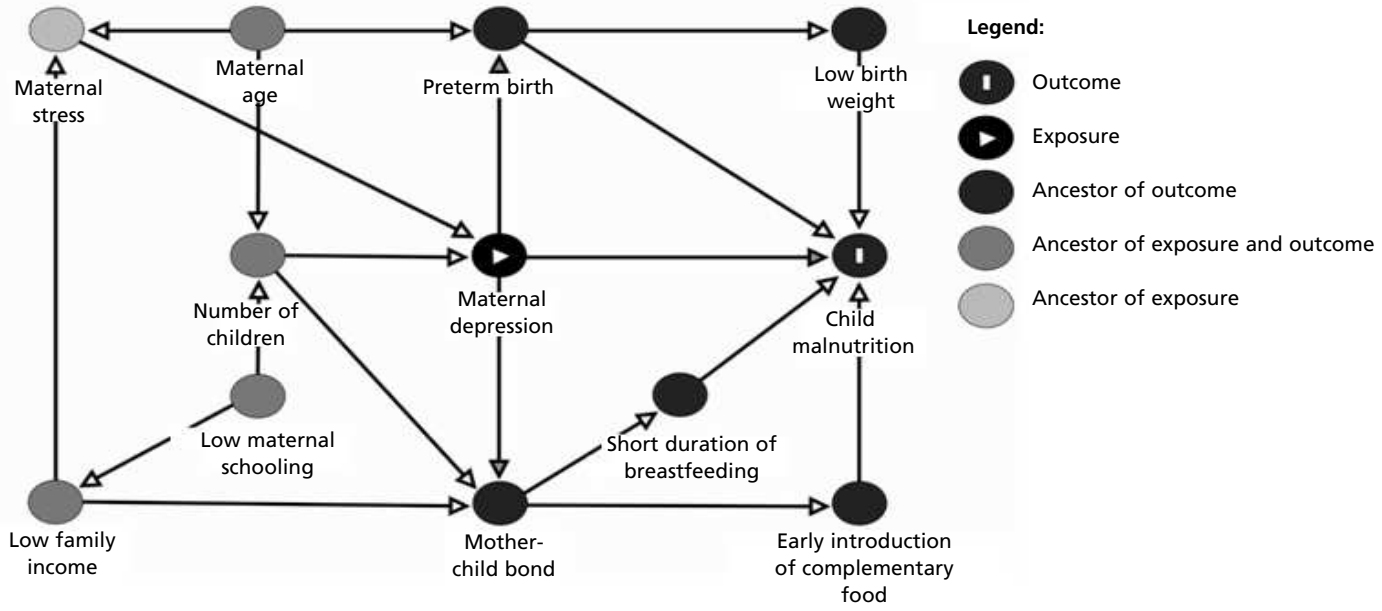

B - Maternal depressive symptoms and child excess weight

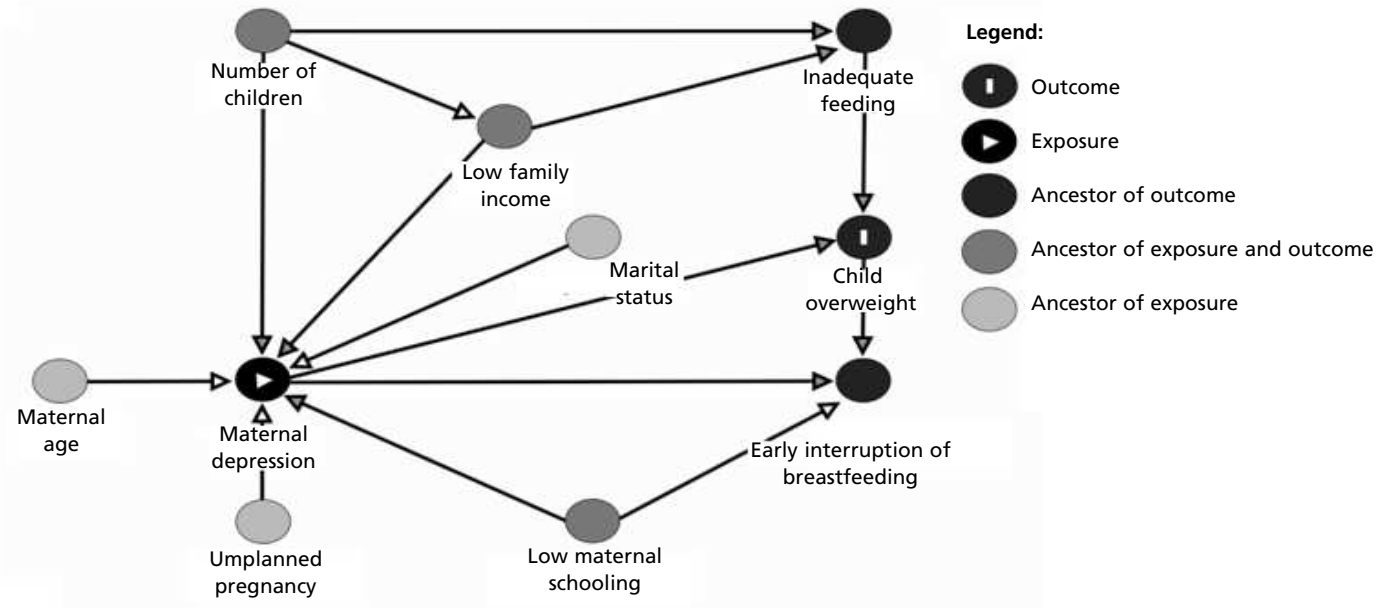

As for family income, $70 \%$ lived with up to two minimum wages. The prevalence of symptoms of prenatal depression was $27.6 \%$ and maternal depression in the second or third year of the child's life was $19.8 \%$ (Table 1). There was no difference in maternal socio-demographic characteristics among mothers who appeared or not at the follow-up in the second or third year of child's life (Table 1).

In the follow-up, $98.8 \%$ of the children were aged 12 to 23 months, with an average of 16 months $(\mathrm{SD} \pm 2.34)$. Prevalences of $6 \%$ of malnutrition $(\mathrm{HAZ}<-2)$ and $10.9 \%$ of excess weight $(\mathrm{BAZ}>+2)$ were found (Table 2). No differences were detected in the characteristics of children, comparing those who appeared or not at the follow-up in the second or third year of life, except regarding birth weight. There was a higher percentage of non-attendance of children that were born with low birth weight (Table 2).

The associations between maternal depressive symptoms and child nutrition without adjustment for confounding factors were not statistically significant (CES-D $\mathrm{p}=0.377$ for malnutrition and $p=0.878$ for excess weight, EPDS $p=0.877$ for malnutrition and $p=0.884$ for excess weight) (Table 3 ).

After adjustment for confounding in the logistic 
Comparison of sociodemographic variables and maternal depression symptoms of the pregnant women of the BRISA cohort, according to attendance at follow-up in the second and third year of their children's life in São Luís, MA, 2010-2011.

\begin{tabular}{|c|c|c|c|c|c|}
\hline \multirow{2}{*}{ Variables } & \multicolumn{2}{|c|}{ Attended } & \multicolumn{2}{|c|}{ Did not attend } & \multirow{2}{*}{$p$} \\
\hline & $\mathrm{n}$ & $\%$ & $\mathrm{n}$ & $\%$ & \\
\hline Age (years) & & & & & 0.498 \\
\hline$<20$ & 121 & 10.7 & 23 & 9.2 & \\
\hline $20-34$ & 919 & 81.3 & 212 & 84.5 & \\
\hline$\geq 35$ & 90 & 8.0 & 16 & 6.3 & \\
\hline Monthly family income (minimum wages) & & & & & 0.516 \\
\hline $\mathrm{MW} \leq 1$ & 267 & 26.9 & 64 & 28.7 & \\
\hline $1<\mathrm{MW}<2$ & 428 & 43.1 & 83 & 37.2 & \\
\hline $2 \leq M W<3$ & 163 & 16.4 & 44 & 19.8 & \\
\hline $3 \leq M W<5$ & 95 & 9.6 & 21 & 9.4 & \\
\hline$M W \geq 5$ & 40 & 4.0 & 11 & 4.0 & \\
\hline Number of children & & & & & 0.476 \\
\hline 1 & 623 & 55.2 & 128 & 52.7 & \\
\hline$\geq 2$ & 506 & 44.8 & 115 & 47.3 & \\
\hline Self reported skin color & & & & & 0.902 \\
\hline White & 182 & 16.4 & 42 & 17.2 & \\
\hline Black & 169 & 15.2 & 39 & 15.9 & \\
\hline Brown skin & 761 & 68.4 & 164 & 66.9 & \\
\hline Marital status & & & & & 0.647 \\
\hline Single & 197 & 17.4 & 44 & 17.5 & \\
\hline Married & 254 & 22.5 & 63 & 25.1 & \\
\hline Consensual union & 823 & 60.1 & 144 & 57.4 & \\
\hline Maternal schooling (years) & & & & & 0.160 \\
\hline 0 a 4 & 17 & 1.5 & 7 & 2.8 & \\
\hline 5 a 8 & 112 & 9.9 & 34 & 13.5 & \\
\hline 9 a 11 & 875 & 77.4 & 182 & 72.5 & \\
\hline$\geq 12$ & 126 & 11.2 & 28 & 11.2 & \\
\hline Planned pregnancy & & & & & 0.684 \\
\hline Yes & 381 & 33.7 & 88 & 35.1 & \\
\hline No & 749 & 66.3 & 163 & 64.9 & \\
\hline Prenatal depressive symptoms (CES-D) 1 & & & & & 0.064 \\
\hline No & 814 & 72.4 & 212 & 67.1 & \\
\hline Yes & 310 & 27.6 & 104 & 32.9 & \\
\hline $\begin{array}{l}\text { Maternal depressive symptoms in the second or } \\
\text { third year of the child's life (EPDS)2 }\end{array}$ & & & & & 0.531 \\
\hline No & 897 & 80.2 & 18 & 85.7 & \\
\hline Yes & 221 & 19.8 & 3 & 14.3 & \\
\hline
\end{tabular}

1 Population Screening Scale for Depression - Center for Epidemiological Studies (CES-D) - Questionnaire applied at the 1st interview; 2 Edinburgh Postpartum Depression Scale (EPDS).

regression models, the associations between maternal depressive symptoms and the nutritional status of the child remained non-significant, with values of $p=0.768$ (CES-D) and $p=0.900$ (EPDS) for association with malnutrition, $p=0,443$ (CES-D) and $p=0,774$ (EPDS) for association with excess weight (Table 4). 
Comparison of demographic variables and anthropometric measurements of the children of the BRISA cohort, according to attendance at follow-up in the second and third year of their life in São Luís, MA, 2010-2011.

\begin{tabular}{|c|c|c|c|c|c|}
\hline \multirow{2}{*}{ Variables } & \multicolumn{2}{|c|}{ Attended } & \multicolumn{2}{|c|}{ Did not attend } & \multirow{2}{*}{$p$} \\
\hline & $\mathrm{n}$ & $\%$ & $\mathrm{n}$ & $\%$ & \\
\hline Age (months) & & & & & 0.760 \\
\hline $12-23$ & 1.117 & 98.8 & 8 & 100.0 & \\
\hline $24-32$ & 13 & 1.2 & 0 & 0 & \\
\hline Sex & & & & & 0.934 \\
\hline Male & 564 & 49.1 & 124 & 50.2 & \\
\hline Female & 566 & 50.1 & 123 & 49.8 & \\
\hline Birth weight (g) & & & & & $<0.001$ \\
\hline$<1500$ & 5 & 0.4 & 6 & 2.5 & \\
\hline $1500-2499$ & 57 & 5.1 & 24 & 9.9 & \\
\hline $2500-3999$ & 994 & 88.3 & 201 & 82.7 & \\
\hline$\geq 4000$ & 70 & 6.2 & 12 & 4.9 & \\
\hline \multicolumn{6}{|l|}{$\mathrm{HAZ} 1$} \\
\hline Malnourished $(S D<-2)$ & 68 & 6.0 & - & - & - \\
\hline Eutrophic (SD $\geq-2)$ & 1.060 & 94.0 & - & - & \\
\hline \multicolumn{6}{|l|}{ BAZ2 } \\
\hline Excess weight & 124 & 10.9 & - & - & - \\
\hline Eutrophic & 1004 & 89.0 & - & - & \\
\hline
\end{tabular}

1 Height-for-age $Z$ score; 2 Z-score of body mass index for age.

\section{Table 3}

Unadjusted analysis of the association between maternal depressive symptoms and child excess weight or malnutrition, BRISA cohort, São Luís, MA, 2010-2011.

\begin{tabular}{|c|c|c|c|c|c|}
\hline Variables & $\mathbf{n}$ & $\%$ & OR1 & $\mathrm{Cl} 95 \% 2$ & $p$ \\
\hline \multicolumn{6}{|l|}{ Excess weight } \\
\hline Prenatal depressive symptoms (CES-D) ${ }^{3}$ & 30 & 9.7 & 0.84 & $0.54-1.31$ & 0.377 \\
\hline $\begin{array}{l}\text { Maternal depressive symptoms in the } \\
\text { second or third year of the child's life } \\
\text { (EPDS) } 4\end{array}$ & 25 & 11.3 & 1.07 & $0.67-1.72$ & 0.878 \\
\hline \multicolumn{6}{|l|}{ Malnutrition } \\
\hline Prenatal depressive symptoms (CES-D) 3 & 19 & 6.2 & 1.09 & $0.62-1.89$ & 0.877 \\
\hline $\begin{array}{l}\text { Maternal depressive symptoms in the } \\
\text { second or third year of the child's life } \\
\text { (EPDS })^{4}\end{array}$ & 13 & 5.9 & 0.96 & $0.51-1.80$ & 0.884 \\
\hline
\end{tabular}

1 Odds Ratio; 2 95\%Confidence Interval; 3 Population Screening Scale for Depression -Center for Epidemiological Studies - Questionnaire applied at the 1st interview; 4 Edinburgh Postpartum Depression Scale. 
Adjusted analysis of the association between maternal depressive symptoms and child excess weight or malnutrition, BRISA cohort, São Luís, MA, 2010-2011.

\begin{tabular}{|c|c|c|c|}
\hline Variables & OR1 & $\mathrm{Cl} 195 \% 2$ & $p$ \\
\hline \multicolumn{4}{|l|}{ Malnutrition } \\
\hline Prenatal depressive symptoms (CES-D)3 & & & 0.768 \\
\hline No & 1.00 & - & \\
\hline Yes & 1.09 & $0.62-1.89$ & \\
\hline Monthly family income (minimum wages) & & & 0.482 \\
\hline$M W \leq 1$ & 1.00 & - & \\
\hline $1<M W<2$ & 0.86 & $0.45-1.64$ & \\
\hline $2 \leq M W<3$ & 1.37 & $0.65-2.88$ & \\
\hline $3 \leq \mathrm{MW}<5$ & 0.62 & $0.20-1.90$ & \\
\hline$M W \geq 5$ & 0.38 & $0.05-2.93$ & \\
\hline Unknow & 0.81 & $0.33-2.00$ & \\
\hline Maternal Age (years) & & & 0.459 \\
\hline$<20$ & 1.00 & - & \\
\hline 20 a 34 & 1.61 & $0.62-4.20$ & \\
\hline 35 & 2.17 & $0.64-7.38$ & \\
\hline Number of children & & & 0.561 \\
\hline 1 & 1.00 & - & \\
\hline$\geq 2$ & 0.86 & $0.51-1.44$ & \\
\hline \multicolumn{4}{|l|}{ Excess weight } \\
\hline Prenatal depressive symptoms (CES-D) ${ }^{3}$ & & & 0.443 \\
\hline No & 1.00 & - & \\
\hline Yes & 0.84 & $0.54-1.31$ & \\
\hline \multicolumn{4}{|l|}{ Monthly family income (minimum wages) } \\
\hline $\mathrm{MW} \leq 1$ & 1.00 & - & \\
\hline $1<M W<2$ & 1.24 & $0.74-2.09$ & \\
\hline $2 \leq \mathrm{MW}<3$ & 1.80 & $0.99-3.28$ & \\
\hline $3 \leq M W<5$ & 1.04 & $0.46-2.33$ & \\
\hline$M W \geq 5$ & 0.45 & $0.10-2.03$ & \\
\hline Unknow & 1.13 & $0.56-2.27$ & \\
\hline Maternal schooling (years) & & & 0.428 \\
\hline 0 a 4 & 1.00 & - & \\
\hline 5 a 8 & 0.65 & $0.37-1.13$ & \\
\hline 9 a 11 & 0.69 & $0.31-1.56$ & \\
\hline$\geq 12$ & 0.34 & $0.04-2.82$ & \\
\hline \multicolumn{4}{|l|}{ Child malnutrition } \\
\hline Maternal depressive symptoms in the second or third year of the & & & 0.900 \\
\hline child's life (EPDS) 4 & 1.00 & - & \\
\hline No & 0.96 & $0.51-1.80$ & \\
\hline \multicolumn{4}{|l|}{ Yes } \\
\hline Monthly family income (minimum wages) & & & 0.498 \\
\hline$M W \leq 1$ & 1.00 & - & \\
\hline $1<M W<2$ & 0.84 & $0.44-1.61$ & \\
\hline $2 \leq M W<3$ & 1.32 & $0.63-2.77$ & \\
\hline $3 \leq \mathrm{MW}<5$ & 0.62 & $0.20-1.89$ & \\
\hline$M W \geq 5$ & 0.36 & $0.05-2.80$ & \\
\hline Unknow & 0.91 & $0.38-2.18$ & \\
\hline
\end{tabular}


Adjusted analysis of the association between maternal depressive symptoms and child excess weight or malnutrition, BRISA cohort, São Luís, MA, 2010-2011.

\begin{tabular}{|c|c|c|c|}
\hline Variables & $\mathrm{OR}^{1}$ & $\mathrm{Cl} 95 \%{ }^{2}$ & $p$ \\
\hline Maternal Age (years) & & & 0.459 \\
\hline$<20$ & 1.00 & - & \\
\hline 20 a 34 & 1.64 & $0.63-4.29$ & \\
\hline$\geq 35$ & 2.16 & $0.64-7.35$ & \\
\hline Number of children & & & 0.547 \\
\hline 1 & 1.00 & - & \\
\hline$\geq 2$ & 0.85 & $0.51-1.43$ & \\
\hline \multicolumn{4}{|l|}{ Child excess weight } \\
\hline $\begin{array}{l}\text { Maternal depressive symptoms in the second or third year of the } \\
\text { child's life (EPDS) } 4\end{array}$ & & & 0.774 \\
\hline No & 1.00 & - & \\
\hline Yes & 1.07 & $0.67-1.71$ & \\
\hline Monthly family income (minimum wages) & & & 0.263 \\
\hline $\mathrm{MW} \leq 1$ & 1.00 & - & \\
\hline $1<\mathrm{MW}<2$ & 1.29 & $0.76-2.19$ & \\
\hline $2 \leq \mathrm{MW}<3$ & 1.87 & $1.02-3.43$ & \\
\hline $3 \leq \mathrm{MW}<5$ & 1.09 & $0.49-2.46$ & \\
\hline$M W \geq 5$ & 0.48 & $0.11-2.19$ & \\
\hline Unknow & 1.18 & $0.59-2.38$ & \\
\hline Maternal education (years) & & & 0.431 \\
\hline 0 a 4 & 1.00 & - & \\
\hline 5 a 8 & 0.65 & $0.37-1.13$ & \\
\hline 9 a 11 & 0.71 & $0.31-1.59$ & \\
\hline$\geq 12$ & 0.35 & $0.04-2.87$ & \\
\hline Number of children & & & 0.704 \\
\hline 1 & 1.00 & - & \\
\hline$\geq 2$ & 0.94 & $0.63-1.38$ & \\
\hline
\end{tabular}

1 Odds Ratio; 2 95\% Confidence Interval; 3 Population Screening Scale for Depression - Center for Epidemiological Studies - Questionnaire applied at the 1st interview; 4 Edinburgh Postpartum Depression Scale.

\section{Discussion}

In the present study, no statistically significant associations were found between maternal depressive symptoms in prenatal period or in the second or third year of the child's life and child malnutrition or excess weight.

Rahman et al.,12 in studies conducted in the rural community of Rawalpindi, Pakistan, 2004, found that children of mothers facing depression during pregnancy were four times more likely to develop malnutrition in the first six months of life, and this risk was two and a half times greater at 12 months of age $(\mathrm{OR}=4.095 \% \mathrm{CI}=2.1-7.7 ; \mathrm{OR}=2.695 \% \mathrm{CI}=$ $1.7-4.1) .12$ Studies suggest that this association is linked to a lack of maternal care and related to a deficient mother-child bond, low family support, precarious economic situation and local customs. 2,5,6,12,25 In rural Bangladesh, located in South Asia, Black et al., ${ }^{26}$ detected, in 2009, the same results as in Pakistan. This study demonstrated that children of mothers with depression symptoms were almost twice more likely to be malnourished $(\mathrm{OR}=2.1795 \% \mathrm{CI}=1.24-3.81, p=0.007)$. However, no associations were found between maternal depression symptoms and infant malnutrition in the studies by Husain et al.,13 (2008) in northeastern England, with children of Pakistani women, and by Harpham et al.,11 in 2002 in three (Ethiopia, India and Peru) of the four countries (Ethiopia, Vietnam, 
India and Peru) where this last study was conducted.

Anoop et al., ${ }^{27}$ in a study carried out in the rural area of Southern India, in 2001, with children of mothers with postpartum depression symptoms, evaluated at the $6^{\text {th }}, 10^{\text {th }}$ and $14^{\text {th }}$ week, and at the $9^{\text {th }}$ and $18^{\text {th }}$ month after delivery, suggest a risk seven and a half times greater for infant malnutrition (OR: 7.4, 95\% CI: 1.6 - $38.5 p=0.01)$. Rahman et al., 12 in a study carried out in Pakistan, 2004, concluded that postpartum depression is associated with child malnutrition. The literature suggests that postpartum maternal depression symptoms influence motherchild interaction and, consequently, maternal care, increasing the risk of child malnutrition. 2,5,6,12,25 However, Harpham et al.,11 have shown that even in countries with high rates of malnutrition, like Ethiopia (38\%) and Vietnam (16\%), the results do not corroborate with those of previous studies. In our study, children of mothers with depression symptoms were not more likely to be malnourished either (OR: 1.09, 95\% CI: $0.62-1.89, p=0.768$ ). Although the studies used the same instruments for weight measurement and assessment of depression symptoms, the results are heterogeneous. This heterogeneity of results may be due to socioeconomic and cultural diversity among studied populations.

In our study, there was no association between maternal depression and excess weight in children. However, Surkan et al.,10 in a study conducted in Teresina, Brazil, in 2002, found an association between maternal prenatal depression and overweight in children between 6 and 24 months, where children exposed to maternal depression symptoms in prenatal period were almost twice more likely to develop overweight $(\mathrm{OR}=1.795 \% \mathrm{CI}=1.4-2.2)$. The literature suggests that the lack of a mother-baby bond and the early introduction of complementary feeding could explain this association. ${ }^{5}$ However, the same results were not found in other studies. Ertel et al., 1 in a study carried out in Boston, USA, in 2002, used two parameters to assess child overweight: subcutaneous skinfolds (subscapular and triceps), and the WHO Weight-for-Height (WHZ) index. Their results showed an association between prenatal maternal depression and overweight in children, considering the parameter of subcutaneous skinfolds, but not the WHZ. ${ }^{1}$ The measurement of subcutaneous skinfolds, however, is no longer frequently used, due to great variation of findings according to the examiner and the method employed. Wojcicki et $a l ., 7$ in a study with US-born Latin children, also used the WHZ indicator to analyze child overweight and also did not find a statistically significant association between maternal prenatal depression and childhood overweight.

Wojcicki et al., ${ }^{7}$ studied the effects of maternal depression in the postpartum period. They found no association with overweight (WHZ $>85^{\text {th }}$ ) or with childhood obesity (WHZ $>95^{\text {th }}$ ), in agreement with our findings. Grote et al.,14 in a study conducted in European countries, also found no differences concerning overweight or obesity comparing children exposed to maternal depression symptoms in the postpartum period with those not exposed. The same results were observed by Surkan et al., 2 in 2001 , in a study carried out in the United States. In the unadjusted model, there was a statistically significant association, but after adjustment, the association was no longer sustained. ${ }^{2}$

In our study, high prevalence of depression symptoms was found in women: $27.6 \%$ of the pregnant women had symptoms of prenatal depression and $19.8 \%$ of the women had symptoms of depression during the child's second or third year of life. In developed countries, these numbers tend to be lower. Ertel et al., 1 in 2002, found prevalence rates of $8.2 \%$ and $7 \%$ of prenatal and postpartum depression, respectively, in women in Boston, USA. Surkan et $a l ., 2$ in 2001 in the United States, found a prevalence of $14 \%$ postpartum depression. In developing and underdeveloped countries, the numbers tend to be similar or higher than those found in our study. Rahman et al.,12 in 2004 in Pakistan, found a prevalence of $25 \%$ of prenatal depression symptoms in women and Black et al.,26 in Bangladesh in 2009, found a prevalence of $45 \%$. Anoop et al.,27 in a study conducted in India in 2001, observed a prevalence of $19.1 \%$ of postpartum depression in women.

Among the limitations of this study, one of them is the fact that we obtained a convenience sample, due to the difficulty of obtaining a random sample of pregnant women. Another limitation was the use of self-administered scales to indicate depression symptoms and also the fact that clinical diagnoses of depression were not performed. However, the use of scales is frequent in epidemiological studies. Two scales were used to measure maternal depression symptoms in two moments: the prenatal period and the child's second or third year of life. This may be a limitation of the study. However, no comparison was made between the prevalence of depression symptoms in the prenatal period and in the second or third year of the child's life. Among the highlights of the study, we cite its prospective design and its large sample size.

Therefore, in this study, no significant associations were found between maternal depression symptoms and the development of child malnutrition 
or excess weight in the first years of life. However, a high prevalence of maternal depression symptoms was found in both periods (prenatal and in the second and third year of the child's life). Therefore, health professionals should be aware of this high

\section{References}

1. Ertel KA, Koenen KC, Rich-Edwards JW, Gillman MW. Antenatal and postpartum depressive symptoms are differentially associated with early childhood weight and adiposity. Paediatr Perinatal Epidemiol. 2010; 24 (2): 17989.

2. Surkan PJ, Ettinger AK, Hock RS, Ahmed S, Strobino DM, Minkovitz CS. Early maternal depressive symptoms and child growth trajectories: a longitudinal analysis of a nationally representative US birth cohort. BMC Pediatr. 2014; 14: 185

3. Wang Y, Lobstein T. Worldwide trends in childhood overweight and obesity. Int J Pediatr Obes. 2006; 1: 11-25.

4. Monasta L, Lobstein T, Cole TJ, Vignerova J, Cattaneo A Defining overweight and obesity in pre-school children IOTF reference or WHO standard? Obes Rev. 2011; 12 (4): 295-300.

5. Santos IS, Matijasevich A, Domingues MR, Barros AJ, Barros FC. Long-lasting maternal depression and child growth at 4 years of age: a cohort study. J Pediatr. 2010 157 (3): 401-6.

6. Surkan PJ, Kennedy CE, Hurley KM, Black MM. Maternal depression and early childhood growth in developing countries: systematic review and meta-analysis. Bull World Health Organ. 2011; 89 (8): 608-15

7. Wojcicki JM, Holbrook K, Lustig RH, Epel E, Caughey AB, Munoz RF, Shiboski SC, Heyman MB. Chronic maternal depression is associated with reduced weight gain in latino infants from birth to 2 years of age. PloS One. 2011; 6 (2): e16737.

8. Elisei S, Lucarini E, Murgia N, Ferranti L, Attademo L. Perinatal depression: a study of prevalence and of risk and protective factors. Psychiatr Danub. 2013; 25 (2): 258-62

9. Seng JS, Oakley DJ, Sampselle CM, Killion C, Bermann GR, Liberzon I. Posttraumatic stress disorder and pregnancy complications. Obstet Gynecol. 2001; 97: 17-22.

10. Surkan PJ, Ryan LM, Carvalho Vieira LM, Berkman LF, Peterson KE. Maternal social and pyschological conditions and physical growth in low-income children in Piaui, Northeast Brazil. Social Sci Med. 2007; 64 (2): 375-88.

11. Harpham T, Huttly S, De Silva MJ, Abramsky T. Maternal mental health and child nutritional status in four developing countries. J Epidemiol Comm Health. 2005; 59 (12): 10604

12. Rahman A, Iqbal Z, Bunn J, Lovel H, Harrington R. Impact of maternal depression on infant nutritional status and illness: a cohort study. Arch Gen Psychiatr. 2004; 61 (9) 946-52. prevalence in order to perform screenings for depression symptoms during these periods and to refer the possible cases for diagnostic confirmation and follow-up by specialists.

13. Husain N, Cruickshank JK, Tomenson B, Khan S, Rahman A. Maternal depression and infant growth and development in British Pakistani women: a cohort study. BMJ Open. 2012; 2 (2): e000523.

14. Grote V, Vik T, von Kries R, Luque V, Socha J, Verduci E, Carlier C, Koletzko B. Maternal postnatal depression and child growth: a European cohort study. BMC Pediatrics. 2010; 10: 14

15. Batistoni SS, Neri AL, Cupertino AP. [Validity of the Center for Epidemiological Studies Depression Scale among Brazilian elderly]. Rev Saúde Pública. 2007; 41 (4): 598-605.

16. Figueira P, Correa H, Malloy-Diniz L, Romano-Silva MA Edinburgh Postnatal Depression Scale for screening in the public health system. Rev Saúde Pública. 2009; 43 (Suppl. 1): 79-84

17. Matijasevich A, Munhoz TN, Tavares BF, Barbosa APPN, Silva DM da, Abitante MS, Dall'Agnol TA, Santos IS. Validation of the Edinburgh postnatal depression scale (EPDS) for screening of major depressive episode among adults from the general population. BMC Psychiatr. 2014; 14: 284 .

18. Cox JL, Chapman G, Murray D, Jones P. Validation of the Edinburgh postnatal depression scale (EPDS) in non-postnatal women. J Affect Disord. 1996; 39: 185-9.

19. WHO (World Health Organization). Training Course on Child Growth Assessment. Geneva; 2008.

20. Cole TJ, Flegal KM, Nicholls D, Jackson AA. Body mass index cut offs to define thinness in children and adolescents: international survey. BMJ. 2007; 335 (7612): 194

21. Onis M, Onyango AW, Borghi E, Garza C, Yang H, Group WHOMGRS. Comparison of the World Health Organization (WHO) Child Growth Standards and the National Center for Health Statistics/WHO international growth reference: implications for child health programmes. Public Health Nutr. 2006; 9 (7): 942-7.

22. WHO (World Health Organization). WHO Anthro for personal computers, version 2, 2007: Software for assessing growth and development of the world's children. Geneva; 2007

23. Li D, Liu L, Odouli R. Presence of depressive symptoms during early pregnancy and the risk of preterm delivery: a prospective cohort study. Hum Reprod. 2009; 24 (1): 14653.

24. Textor J, Hardt J, Knuppel S. DAGitty: a graphical tool for analyzing causal diagrams. Epidemiol. 2011; 22 (5): 745.

25. Duarte CS, Shen S, Wu P, Must A. Maternal depression and 
child BMI: longitudinal findings from a US sample. Pediatr Obes. 2012; 7 (2): 124-33.

26. Black MM, Baqui AH, Zaman K, El Arifeen S, Black RE. Maternal depressive symptoms and infant growth in rural Bangladesh. Am J Clin Nutr. 2009; 89 (3): 951S-7S.
27. Anoop S, Saravanan B, Joseph A, Cherian A, Jacob KS Maternal depression and low maternal intelligence as risk factors for malnutrition in children: a community based case-control study from South India. Arch Dis Childhood. 2004; 89 (4): 325-9.

Received on September 8th, 2016

Final Version Presented on April 9th, 2017

Approved on April 19th, 2017 